\title{
The Importance of Followership and Reputation in an HR consulting firm
}

\section{Debra Finlayson and William S. Harvey}

Ten years ago, Sarah Randall was captivated and inspired by a conversation with a job candidate, Dan Hartman. During the interview, Dan shared his ideas about being an 'Employer of Choice'. Sarah was so impressed by the interview that she asked Dan if he would be interested in forming a company that assists other companies to become employers of choice; Dan asked if he could have a day to think about it. When he called back the next day, Dan said yes, and that began a collaboration which continues today. Sarah is now the CEO and Founder of the company they created, Higher Steps HR Consulting.

The core business of Higher Steps is to examine organizations through the use of HR audits, analysis, and recommendations. It consists of senior independent human resources consultants who bring together their unique and extensive individual expertise, which spans the entire body of HR knowledge, to provide a single source solution for clients. Higher Steps aims to close any gaps between client expectations before a project and their experiences during a project. Typically, there is a lot of rhetoric from consultancy firms during the tendering process and Higher Steps ensures it is as transparent as possible and that it only promises what it can deliver on.

Sarah purposely does not micromanage her consultants, but she does occasionally remind them of the dynamic in which they work, and the importance of positioning themselves as a neutral party with clients. A common thread running through the group is their high level of mutual respect for each other. Their notable pride in being part of a reputable firm has resulted in a collective brainpower and expanded suite of resources upon which all who contribute have 
come to rely. In other words, their collective reputation is greater than the sum of their individual parts.

Collaboration is fundamental to the culture. Sarah brings the consultants together for quarterly team meetings and all eagerly anticipate hearing about the projects on which each person is working. These meetings provide an opportunity for receiving expert input where needed, as well as an opportunity to learn from the expertise and experience of other team members, which would not be available to them if they were solely independent consultants.

Transparency is a key operational strategy at Higher Steps. Sarah maintains that, whenever a decision is to be made, she runs it by the team prior to its implementation. Thus, each consultant is aware of what is going on and they are consulted as a group if a pending decision will affect them.

Sarah brings numerous additional qualities to Higher Steps, but admits that it would not exist today without the tenacity that all have demonstrated in developing and promoting the business. She values the organization's diverse relationships with the business community. Sarah's respect for her team members is mutual; the consultants describe Sarah as a mastermind and visionary, consistently collaborative, transparent, and always respectful. Dan Hartman notes,

While Sarah remains open to feedback she has always exhibited confidence when it comes to making key decisions. She clearly demonstrates just how much she values her clients and consultants. These abilities help to draw people together to make a difference on behalf of the greater organization. Yet, Sarah is not a pushover and, when needed, has difficult conversations about loyalty to the firm, 
and maintaining a high standard of quality. (D. Hartman, personal interview)

Reputation is paramount to Higher Steps, especially as it is a service-based business with a lot of competition. The senior consultants have earned reputations as experts in the HR industry; some as generalists and others as specialists in organizational development, recruitment and retention, leadership training, total compensation and more. All the consultants have built their careers through single or multi organizational paths and have developed successful independent consulting companies alongside working for Higher Steps, which Sarah has encouraged. The Higher Steps team is a cooperative group of HR experts well positioned to support and realize their clients' desire to become employers of choice.

\section{Scholarly Commentary}

The literature on leadership has typically focused on leaders and performance while overlooking the importance of followers (Meindl \& Ehrlich, 1987). Riggio (2014) argues that we need to better understand how leaders and followers "co-produce" leadership, while other scholars have emphasized a follower-centric approach to overcome the historical bias of only analysing leaders (Bligh \& Kohles, 2012; Haslam, Reicher, Millard, \& McDonald, 2015; UhlBien, Riggio, Lowe, \& Carsten, 2014). Understanding followership is imperative today given the importance of working in teams, particularly among professional service firms (Gardner, 2015), which are typically less vertical and more horizontal in structure (Carsten, Uhl-Bien, West, Patera, \& McGregor, 2010). Therefore, it is essential to understand both leaders and followers in the context of co-leadership because both have a significant impact upon their collective corporate and individual reputations. 
Corporate reputation is understood as the aggregated perceptions of an organization held by stakeholders in relation to the organization's competitors. Reputation, i.e., "what do stakeholders actually think about us", is also similar to a number of related concepts such as identity (who we are as an organization), intended image (how we want others to think about us) and construed image (what do we believe others think about us) (Brown, Dacin, Pratt, \& Whetten, 2006, p. 102). Understanding these different concepts will benefit organizations because there are often subtle differences in how internal and external stakeholders perceive organizations, and yet it is important that these perceptions are consistent otherwise stakeholders will questions such differences.

A positive reputation is vital in attracting and retaining key talent, which enables the firm to charge higher prices and, over time, leads potential and existing clients to assume that the organization provides a high quality service (Fombrun, 1996; Harvey \& Morris, 2012). This is important since a positive reputation helps attract and retain the best followers. The reason for this is because individuals want to work for and remain working for organizations and leaders with positive reputations, especially since this casts a halo over their own individual reputations.

Furthermore, the growing emphasis on sound ethics has led to Trevino, Brown, and Hartman (2003) to claim that an executive's reputation for ethical leadership is as important as ever in influencing followers' impressions of these leaders and their organizations, which in turn will affect followers' motivation and performance. Huang, Wang, and Hie (2014) linked leadermember exchange (LMX) with organizational citizenship behaviors (OCBs) discovering that, when a follower has a favourable perception of the leader's external image, one that matches the follower's self-identity, it leads to higher quality relationships and more motivation to perform 
OCBs. Furthermore, positive leader reputation is built when leaders share their expertise with less knowledgeable followers (Thomas \& Hirschfeld, 2015).

Ehrhart (2012) posits followers' self-concepts (self-construal) can be linked to leader and organisational goals, whereby the followers' ILT (implicit leader theories) uniquely vary with their personalities, values, and other characteristics. Proactive followership behaviors can directly enhance a manager's overall effectiveness by directly contributing to the positive reputations of leaders, organizations and performance outcomes. In short, leader reputation is positively correlated with engaged followership.

One example of engaged followership is a transcendent follower, who is "someone who expresses competence in terms of their management of relations with self, others and organization" (e Cunha et al., 2013, p. 87). In particular, a transcendent follower embraces three critical capabilities: (a) a responsible self-manager, (b) the ability to build and sustain rich constructive relationships with peers and leaders to acquire social capital, and (c) the ability to help build vigilant organizations through extra role behaviors (e Cunha et al., 2013). Moreover, new to the followership literature is the concept of the zone of stewardship, which is when followers 'go the extra mile' for their organizations and are fully committed and engaged to achieve the best in the interests of their organizations (Hayes et al., 2015, p. 275). The authors assert that if leaders treat employees as valued partners, a trust culture ensues which enhances OCBs, and thus to increased profitability through engaged followership. Higher Steps consultants exhibit transcendent follower attributes in having strong self-leadership as independent consultants, bringing social capital from careers full of rich business relationships, and also demonstrating extra role behaviour in their willingness to collaborate with stewardship on projects in spite of not being the assigned project lead. These extra role behaviors further 
enrich their social capital within the Higher Steps team, and help to build the firm's reputation among clients.

Arguably, Sarah has become a successful business leader in part influenced by the consultants, who exhibit transcendent followership, contributing within and across each of the levels of self, others, and organization (e Cunha et al., 2013). Identity strength (credibility) and immediacy (perceived psychological social distance) are key moderators of influence that followers have with leaders (Oc \& Bashur, 2013, p. 924). Followers' influence can be strengthened when leaders have "information dependence", relying on followers for information, or "effect dependence", relying on followers for social affiliation or positive self-regard (Oc \& Bashshur, 2013).

It is clear from our interviews and participant observation that it is through Sarah's predisposition for social charismatic leadership (SCL), envisioning a better state for organizations, being collectively orientated, egalitarian and non-exploitive, that she attracts the consultants to engage in realizing her vision. Thus, their intrinsic motivation (susceptibility for meaning, competence, self-determination and impact) is sparked through their ILT's. Additionally, leaders with a strong reputation for SCL attract proactive followership styles, which further enhance a leader's confidence that their followers will provide the necessary input, so the vision is truly shared (Lapierre, Bremner, \& McMullen, 2012). Engagement now becomes reciprocal, perpetual and generative.

Higher Steps has moved to being an employer of choice by embracing an inclusive talent management approach (Martin, 2009), which sees talent distributed throughout the organization and opportunities for self-development as fundamental through assigned projects and expert peer support in which all members engage. This poses a curious dilemma of determining who leads 
and who follows. Tanoff and Barlow (2002) noted that the difference between leadership and followership constructs is not as simple as strong followers emulate their leader, and the authors concluded that Kelley's (1992) behaviours of exemplary 'proactive' followers were very similar to the behaviours that effective leaders showed.

\section{Conclusion}

Sarah's careful choice of who would come onto the team of consultants further illustrates the importance of followership for leadership effectiveness. At the same time, without Sarah's leadership qualities, consultants would not remain working at Higher Steps. This illustrates the impact a leader's reputation has on an organization's followership and vice-versa.

It is difficult to predict exactly where Higher Steps will be in two or even five years given the changing landscapes of organizations today. However, as noted by Martin (2009), "Good governance and leadership, supported by good 'followership', helps to bind an organization together as it changes" (p. 223). 


\section{Discussion Questions}

1. What role, if any, does Sarah's reputation with her team play in the overall collaboration of the group? In what ways does her reputation impact the team, and does it extend beyond the organization to its interactions with clients?

2. Based on the evidence from the case, do you believe that Higher Steps is an Employer of Choice?

3. In what ways is Higher Steps' approach to empowering its workers transferrable to other organizations?

4. If you were a human resources consultant, would you want to work for Higher Steps? Why, or why not? What are all the benefits of the Higher Steps approach, and what are the downsides?

5. In what ways can followership influence the reputation of an organization and/or its leaders? 


\section{References}

Bligh, M. C., \& Kohles, J. C. (2012). Approaching leadership with a follower focus. Zeitschrift Für Psychologie, 220(4), 201-204. doi:10.1027/2151-2604/a000114

Brown, T. J., Dacin, P. A., Pratt, M. G., \& Whetten, D. A. (2006). Identity, intended image, construed image, and reputation: An interdisciplinary framework and suggested terminology. Journal of Academy of Marketing Science, 34(2), 99-106. doi:10.117/0092070305284969

Carsten, M. K., Uhl-Bien, M., West, B. J., Patera, J. L., \& McGregor, R. (2010). Exploring social constructions of followership: A qualitative study. The Leadership Quarterly, 21(3), 543562. doi:10.1016/j.leaqua.2010.03.015

Crossan, M., Vera, D., \& Nanjad, L. (2008). Transcendent leadership: Strategic leadership in dynamic environments. The Leadership Quarterly, 19(5), 569-581. doi:10.1016/j.leaqua.2008.07.008

DeRue, D. S., \& Ashford, S. J. (2010). Who will lead and who will follow? A social process of leadership identity construction in organizations. Academy of Management Review, 35(4), 627-647. doi:10.5465/AMR.2010.53503267

e Cunha, M. P., Rego, A., Clegg, S., \& Neves, P. (2013). The case for transcendent followership. Leadership, 9(1), 87-106. doi:10.1177/1742715012447006

Ehrhart, M. G. (2012). Self-concept, implicit leadership theories, and follower preferences for leadership. Zeitschrift für Psychologie, 220(4), 231-240. doi:10.1027/2151-2604/a000117

Fombrun, C. J. (1996). Reputation: Realizing value from the corporate image. Boston, MA: Harvard Business School Press. 
Gardner, H. K. (2015). When senior managers won't collaborate. Harvard Business Review, 73(2), pp. 75-85. Retrieved from: https://hbr.org/2015/03/when-senior-managers-wont-

collaborate

Harvey, W. S., \& Morris, T. (2012). A labor of love? Understanding reputation formation within the labour market. In M.L. Barnett and T.G. Pollock (Eds.) The Oxford handbook of corporate reputation (pp. 341-360). Oxford, England: Oxford University Press.

Haslam, S. A., Reicher, S. D., Millard, K., \& McDonald, R. (2015). Happy to have been of service: The Yale archive as a window into the engaged followership of participants in Milgram's ‘obedience’ experiments. British Journal of Social Psychology, 54(1), 55-83. doi:10.1111/bjso.12074

Hayes, L. A., Caldwell, C., Licona, B., \& Meyer, T. E. (2015). Followership behaviors and barriers to wealth creation. Journal of Management Development, 34(3), 270-285. doi:10.1108/JMD-09-2013-0111

Huang, J., Wang, L., \& Xie, J. (2014). Leader-member exchange and organizational citizenship behavior: The roles of identification with leader and leader's reputation. Social Behavior and Personality: An International Journal, 42(10), 1699-1711. doi:10.2224/sbp.2014.42.10.1699

Kelley, R.E. (1992). The power of followership. New York, NY: Doubleday Business.

Lapierre, L. M., Bremner, N. L., \& McMullan, A. D. (2012). Strength in numbers: How employees' acts of followership can influence their manager's charismatic leadership behavior. Zeitschrift für Psychologie, 220(4), 251-261. doi:10.1027/2151-2604/a000119

Martin, G. (2009). Driving corporate reputations from the inside: A strategic role and strategic dilemmas for HR? Asia Pacific Journal of Human Resources, 47(2), 219-235. 
doi:10.1177/1038411109105443

Meindl, J. R., \& Ehrlich, S. B. (1987). The romance of leadership and the evaluation of organizational performance. Academy of Management Journal, 30(1), 91-109.

Oc, B., \& Bashshur, M. R. (2013). Followership, leadership and social influence. The Leadership Quarterly, 24(6), 919-934. doi:10.1016/j.leaqua.2013.10.006

Riggio, R. E. (2014). Followership research: Looking back and looking forward. Journal of Leadership Education, 13(4). doi:10.12806/V13/I4/C4

Tanoff, G. F., \& Barlow, C. (2002). Leadership and followership: Same animal, different spots. Consulting Psychology Journal: Practice and Research, 54(3), 157-167. doi:10.1037//1061-4087.54.3.157

Thomas, C. H., \& Hirschfeld, R. R. (2015). Knowing is half the battle: Interdependent effects of knowledge and action on leader emergence. Leadership \& Organization Development Journal, 36(5). doi:10.1108/LODJ-09-2013-0125

Trevino, L. K., Brown, M., \& Hartman, L. P. (2003). A qualitative investigation of perceived executive ethical leadership: Perceptions from inside and outside the executive suite. Human Relations, 56(1), 5-37. doi:10.1177/0018726703056001448

Uhl-Bien, M., Riggio, R. E., Lowe, K. B., \& Carsten, M. K. (2014). Followership theory: A review and research agenda. The Leadership Quarterly, 25(1), 83-104. doi:10.1016/j.leaqua.2013.11.007 


\section{Debra Finlayson, BBA, Post Baccalaureate HRM, MA, CHRP}

Debra Finlayson is a Human Resources Consultant specializing in workforce development. As the Manager, Member Relations for the Human Resources Management Association she oversaw 70+ volunteers delivering the professional development and regional services for 2000+ members. Debra's 2014 MA dissertation focused on linking two leadership paradigms: followership and professional reputation. She will focus her PhD work on advancing research and understanding of the cultural and global impacts of followership and teach and support organizations in the development of followership within strategic planning. Debra currently sits as the Chair for the Human Resources Advocacy Team with the Surrey Board of Trade assigned to the creation of their municipal Workforce Development Plan.

\section{William S. Harvey, BA, MPhil, PhD, MCIPD}

William Harvey is Research Director and Senior Lecturer at the University of Exeter Business School. William has published in a range of journals in business and management, sociology, geography and industrial relations including: Work, Employment and Society, Journal of Management Development, Work and Occupations, Employee Relations, Population, Space and Place, Qualitative Research, Global Networks, Asian Population Studies and Geoforum. He has co-edited a book with Cambridge University Press on International Human Resource Management and has a co-authored book on leadership forthcoming with Cambridge University

Press. William has taught undergraduate, postgraduate, MBA and EMBA students at the University of Cambridge, the University of Oxford, the University of British Columbia, the University of Sydney and the University of Exeter. 